University of Nebraska - Lincoln

DigitalCommons@University of Nebraska - Lincoln

Faculty Publications, Department of Psychology

Psychology, Department of

6-1-2005

\title{
Clinical Decision-Making about Psychopathy and Violence Risk Assessment in Public Sector Mental Health Settings
}

Eric B. Elbogen

Duke University Medical Center, eric.elbogen@duke.edu

Matthew T. Huss

Creighton University, mhuss@creighton.edu

Alan Tomkins

University of Nebraska, atomkins@nebraska.edu

Mario J. Scalora

University of Nebraska-Lincoln, mscalora1@unl.edu

Follow this and additional works at: https://digitalcommons.unl.edu/psychfacpub

Part of the Psychiatry and Psychology Commons

Elbogen, Eric B.; Huss, Matthew T.; Tomkins, Alan; and Scalora, Mario J., "Clinical Decision-Making about Psychopathy and Violence Risk Assessment in Public Sector Mental Health Settings" (2005). Faculty Publications, Department of Psychology. 16.

https://digitalcommons.unl.edu/psychfacpub/16

This Article is brought to you for free and open access by the Psychology, Department of at DigitalCommons@University of Nebraska - Lincoln. It has been accepted for inclusion in Faculty Publications, Department of Psychology by an authorized administrator of DigitalCommons@University of Nebraska - Lincoln. 


\title{
Clinical Decision-Making about Psychopathy and Violence Risk Assessment in Public Sector Mental Health Settings
}

\author{
Eric B. Elbogen \\ Duke University Medical Center \\ Matthew T. Huss \\ Creighton University \\ Alan J. Tomkins \\ Mario J. Scalora \\ University of Nebraska Public Policy Center \\ University of Nebraska-Lincoln
}

\begin{abstract}
Although there has been extensive research on psychopathy, it is unknown how, or whether, clinicians in public sector mental health settings consider the Psychopathy Checklist (PCL) for assessing violence risk. Mental health clinicians $(N=135)$ from 4 facilities were interviewed by using multiple methods for collecting data on decision making. Participants considered clinical information most often when assessing violence risk, indicating that these data were most readily available. Clinicians perceived formal testing results (e.g., PCL) to be least available and considered testing least often, especially if clinicians had less clinical experience. Participants did not explicitly report using the PCL but did implicitly rely on psychopathy factors when assessing violence risk. Clinicians in crisis settings reported less availability of historical data typically needed for the PCL. The data point to specific ways to improve the clinical practice of violence risk assessment in public mental health settings.
\end{abstract}

Keywords: violence risk assessment, psychopathy, clinical decision making, mental health services research, public sector mental health

Over the past decade, there has been extensive research on violence risk assessment in psychiatric settings (for review, see Grisso \& Tomkins, 1996). This research has attempted to identify risk factors that show strong relationships with violence (McNiel, 1998; Monahan \& Steadman, 1994). As a result, researchers have sought to develop actuarial risk assessment tools (Borum, 1996) to help improve clinicians' ability to evaluate patients' risk of violent behavior in practice by statistically optimizing predictions of violence (Gardner, Lidz, Mulvey, \& Shaw, 1996a, 1996b). There have been several actuarial violence risk assessment tools that have been or are currently being developed for use with clinical populations in civil and forensic psychiatric contexts (e.g., Violence Risk Ap- praisal Guide: Quinsey, Harris, Rice, \& Cormier, 1998; HCR-20: Webster, Douglas, Eaves, \& Hart, 1997; Iterative Classification Tree: Monahan et al., 2005).

Each of these tools utilizes psychopathy, which has shown a consistently robust relationship with violence. Indeed, psychopathy as measured by the Psychopathy Checklist (PCL; Hare, 1991) is one of the strongest predictors in the aforementioned instruments (e.g., Harris, Rice, \& Cormier, 2002). The PCL, now the PCL-Revised (Hare, 2003), uses a semistructured interview and a thorough chart review to arrive at a total psychopathy score. The PCL-Revised is also scored along two broad factors: (a) an affective-interpersonal factor (characterized by lack of empathy, deceitfulness, lack of remorse, and failure to accept responsibility)

Eric B. Elbogen. Department of Psychiatry, Duke University Medical Center; Matthew T. Huss, Department of Psychology. Creighton University: Alan J. Tomkins, University of Nebraska Public Policy Center; Mario J. Scalora, Department of Psychology, University of Nebraska-Lincoln. We thank Steve Penrod, John Monahan, Joel Dvoskin, and Jeff Swanson for helpful comments on a draft of this article. Eric B. Elbogen was supported as a predoctoral fellow in the University of Nebraska Law/Psychology Program by National Institute of Mental Health Training Grant 5T32MH16156 for "Training in Mental Health and Justice Systems Research” during the preparation of this article. Corresponding author: Eric B. Elbogen; email: eric.elbogen@duke.edu

"This article may not exactly replicate the final version published in the APA journal. It is not the copy of record." Copyright (C) 2005 American Psychological Association. Used by permission. http://www.apa.org/journals/ser/ 
and (b) a socially deviant factor (characterized by lack of realistic goals, irresponsibility, impulsivity, juvenile delinquency, and poor behavioral controls). Although a few researchers disagree (Gendreau, Goggin, \& Smith, 2002), meta-analytic reviews indicate that psychopathy is one of the strongest risk factors for assessing violence across a number of populations (Salekin, Rogers, \& Sewell, 1996; Skeem, Edens, \& Camp, 2004). This relationship has been demonstrated in a variety of populations (Barbaree, Seto, Langton, \& Peacock, 2001; Bovasso, Alterman, Cacciola, \& Rutherford, 2002; Edens, Skeem, \& Cruise, 2001; Grann, Langstrom, Tengstrom, \& Kullgren, 1999; Grann \& Wedin, 2002; Looman, Abracen, \& Serin, 2005; Louth, Hare, \& Linden, 1998; Skeem \& Mulvey, 2001). As a result, Salekin et al. (1996) noted that psychopathy was critical to consider for predicting violence risk.

Although there has been much research on what factors clinicians should use for assessing violence risk in practice (such as psychopathy), there has been relatively less empirical research on what clinicians do use in real-world clinical settings. Mulvey and Lidz (1985, p. 215) stated that "it is only in knowing 'how' the process [of risk assessment] occurs that we can determine both the potential and the strategy for improvement in the prediction of dangerousness. Addressing this question requires systematic investigation of the possible facets of the judgment process." In other words, it will not matter whether a particular risk factor predicts violence if no effort is made to determine whether or how those risk factors actually are used in practice. Until more is understood about the process of violence risk assessment, it may be difficult to incorporate empirical findings into clinically useful information.

As a result, descriptive studies aimed at getting a picture of violence risk assessment are necessary in order to enhance violence risk assessments in practice. The following questions remain: Do clinicians in the public sector consider the PCL when assessing violence risk of psychiatric patients? If not, what types of factors do clinicians say they rely most on to reach risk judgments? Do clinician characteristics influence violence risk assessment and use of the PCL? If so, how? Do clinicians perceive PCL results to be available to them in practice? What variables might affect these perceptions? The purpose of this study was to address these questions by using a multimethod de- sign to investigate clinical decision making about psychopathy and violence risk assessment in public sector mental health settings.

\section{Method}

\section{Settings}

Mental health professionals were solicited from four adult inpatient psychiatric facilities in Nebraska. Three of these-the short-term care program, community transition program, and forensic program-are located at a 240-bed state-operated psychiatric hospital that serves most of the severely mentally ill patients in the state. Half of the beds are housed in the forensic unit, providing evaluation and treatment services for adult male offenders found or awaiting evaluation for insanity and competency as well as mentally disordered sex offenders. Civilly committed adult patients are first treated in the 40-bed short-term care program for stabilization, where the average stay is 2 months. If patients require more intensive care, they are treated at the 40-bed community transition program, a facility offering extensive psychosocial rehabilitation for long-term patients. Three psychologists on the campus trained in the PCL administered risk assessments at the request of a patient's treatment team.

The fourth facility, the crisis center, is located within the local community mental health center and consists of a 15-bed unit that serves as the initial gateway for longer term inpatient mental health services. Patients in crisis, either at risk to harm themselves or others, are brought to the crisis center so that they can be evaluated for the appropriateness of civil commitment. The crisis center receives over 50 admissions per month, with an average length of stay of 12 days. Patients are discharged to the community or transferred to other inpatient facilities, typically the state hospital. There was one psychologist on staff at the crisis center trained to conduct formal violence risk assessment if requested.

\section{Participants}

In the current study, a total of 135 mental health professionals and paraprofessionals volunteered to participate in clinician interviews (out of 210 clinicians and technicians, representing a 64\% response rate). Participation was generally consistent across the sites (crisis cen- 
ter: $n=20$, out of 32 ; short-term care program: $\mathrm{n}=$ 30 , out of 54; forensic unit: $n=53$, out of 83 ; and the community transition program: $n=32$, out of 41 . Participants included professional staff $(\mathrm{n}=68)$ nurses (43\%), psychiatrists (5\%), clinical psychologists (19\%), and master's level social workers or psychologists (33\%) —and paraprofessional staff ( $n$ $=67$ ). The participants (73 female, 62 male) primarily were Caucasian $(n=126)$. Nonwhite participants were from the following backgrounds: African American $(n=4)$, Asian-Pacific $(n=2)$, Hispanic $(n=2)$, and Native American $(n=1)$. The median age of the participants was 39 years. The average clinical experience with psychiatric populations was 11.6 years $(S D=8.23)$.

We were especially interested in including nurses and technicians because, according to the National Institute of Justice, frontline staff in mental health settings are just as likely to be victims of patient aggression as physicians are, they experience 68 incidents of nonfatal patient violence per 1,000 workers, and they thus engage in one of the most risky occupations in which to become a victim of nonfatal violence (Bureau of Justice Statistics, 2000). Although it is important to note that only psychologists and psychiatrists can administer the PCL, the information the PCL generates about violence risk can be used by any mental health professional or paraprofessional. In this study, participants were included only if they attended multidisciplinary patient treatment meetings in which information about a patient's violence risk-including results from any risk assessments conducted-was discussed extensively, evaluated formally, and incorporated directly into both inpatient and outpatient planning.

\section{Design and Procedure}

Participants were interviewed for this study from August 1998 until April 1999. Interviews lasted approximately $45 \mathrm{~min}$. Copies of sign-up times were left in staff's mailboxes at each of the settings above. Individuals who volunteered to participate were interviewed as part of a broader study of violence risk assessment. Participants gave informed consent and were randomly assigned to either admission or discharge conditions because it has been argued that treatment setting may define the task of violence risk assessment (Heilbrun, 1997; Mulvey \& Lidz, 1995). Participants were thus prompted to think about violence risk assessment for recently admitted patients or for patients on discharge status. Each participant interview involved three distinct sections.

1. Clinical consideration of risk factors. Participants were provided the current patient census and asked to list the first names of any eight patients from the census (either recently admitted or on discharge status based on the assigned condition). On a computer, participants typed in first names of these patients. The screen then prompted participants in an open-ended manner to list risk factors they used to assess violence potential of these patients: "List one important factor you use to assess a patient's risk of dangerousness to others.” Participants then entered eight distinct risk cues. In pilot studies, 10 patients and 10 risk factors were originally elicited, but these interviews lasted more than an hour. Thus, data collection was condensed to be more time efficient.

Risk cues were exported onto a spreadsheet. A coding scheme was constructed to approximate the risk domains from the MacArthur Violence Risk Assessment Study (Steadman et al., 1994). Research assistants coded risk cues into the following domains: (a) clinical: diagnosis, personality characteristics, and psychological conditions; (b) history: data on patient's past related to violent behavior or patient's past background; (c) contextual: environmental factors of risk of violence; (d) dispositional-demographic: demographic and/or physical data; and (e) dispositional-testing: data from actuarial measures, risk tools, or psychological tests.

Two research assistants were provided with this coding scheme and asked to independently code each individual risk cue in the spreadsheet. An interrater reliability of $\kappa=.89$ was calculated for a total of 1,080 risk factors coded by the two research assistants. For the cues for which there was disagreement, the two coders discussed differences, achieved consensus, and provided final ratings, reported in the results below. It should be noted that research assistants also tabulated the number of times each risk cue was listed (e.g., how many times was "psychopathy" listed?), thereby enabling analysis of the most frequently considered individual risk cues.

2. Clinical decision-making task. During the second phase of the interview, participants entered data on a computer program in which they were asked to rate the eight patients listed in Phase 1 on a Likert 
scale (1 to 8$)$ on cues derived from the 12 items on the PCL: Screening Version (PCL:SV; Hart, Hare, \& Forth, 1994), including grandiosity, impulsivity, juvenile antisocial behavior, adult antisocial behavior, lacking remorse, irresponsibility, deceitfulness, poor behavioral controls, failing to take responsibility, superficiality. lacking goals, and lacking empathy. Participants were not asked to formally score the patients according to the PCL:SV but to instead rate the patients on the items that compose the PCL:SV. Participants also rated dangerousness for each patient on a scale from 1 (not dangerous to others) to 8 (very dangerous to others). Again, in pilot studies the scale was condensed to an 8-point scale in order to reduce administration time. A total of 1,080 judgments of dangerousness were obtained.

A random-effects design was used. This clinical decision-making task involved eliciting judgments for patients (stimuli) that participants themselves chose. Random-effects designs are used frequently in sociological research (e.g., see Hox \& Kreft, 1994) and are statistically complex because they render a different number of ratings for different subjects (Keppel, 1991). For example, in this study, 6 participants might have rated one patient, whereas only 1 participant might have rated another patient. We followed recommendations by Leger and Didrichsons (1994) on random-effects design data and pooled the 1,080 ratings, with each-considered as an independent data point.

3. Perceptions of risk factor availability. In the final part of the interview. participants completed a survey in which they rated the availability of a number of risk cues. These cues included the PCL as well as cues derived from the Violence Risk Appraisal Guide (Quinsey et al., 1998), the HCR-20 (Webster et a]., 1997), and the MacArthur Violence Risk Assessment Study (Steadman et al., 1994). Because of the large number of cues this involved, and in order to make the survey more user-friendly and time efficient, broader terms were used to substitute for cues in which two or more instruments used different words to describe approximately the same concept (e.g., instead of rating both "history of crime and violence" from the MacArthur Study and "previous violence" from the HCR-20, participants rated perceived availability of "history of violence”).

This resulted in a survey form with a total of 58 cues divided among the MacArthur risk domains described above (clinical, historical, testing, contextual). A composite score for each domain was calculated as the average ratings for cues within that domain were averaged. Demographic data were always available and therefore not rated. On the form, participants were asked, "How accessible is this information to you?" and prompted to rate each risk cue for perceived relevance on a scale from 0 (not available) to 10 (very available). Condensing the scale did not appear to affect administration time in pilot studies, so it remained $0-10$. For the survey, participants received instructions to think about how they assessed violence risk in general; participants were not asked to consider how they assessed cue availability in the context of any particular patient.

\section{Results}

\section{Clinical Consideration of Risk Cues}

Descriptive analyses were used to examine the types of risk cues participants reported using to assess violence risk for actual patients on the current census. Overall, clinicians listed clinical variables most often and testing information least often. This overall pattern of consideration of cue domains did not differ by clinical context. Indeed, the majority of the participants (82\%) listed four or more clinical cues when they were asked to list eight cues they considered for assessing actual patients' violence risk. However, Table 1 shows that $75 \%$ of all risk cues listed by paraprofessionals were in the clinical domain, compared with $65 \%$ for professionals, $F(1,133)=4.93, p=.02$. There were no other differences between professionals and paraprofessionals in decision making. Still, clinicians with more than 11 years of experience with psychiatric populations - those above the meanwere more likely to consider testing results, $F(1$, $133)=8.45, p=, 004$, and demographic data, $F(1$, $133)=10.69, p=.001$, than were less experienced clinicians when assessing patients' violence risk. The data indicated that among the most commonly considered cues were history of violence (66\%), medication noncompliance (33\%), substance abuse (28\%), and poor anger control (21\%). It is also important to note that psychopathy was not listed among the total 1,080 cues provided by participants. 
Table 1

Clinical Decision Making of Violence Risk: A Comparison of Professional and Paraprofessional Staff

\begin{tabular}{|c|c|c|c|c|c|c|}
\hline \multirow[b]{2}{*}{ Cue domain } & \multicolumn{2}{|c|}{ Professional } & \multicolumn{2}{|c|}{ Paraprofessional } & \multirow[b]{2}{*}{$F$} & \multirow[b]{2}{*}{$p$} \\
\hline & $M$ & $S D$ & $M$ & $S D$ & & \\
\hline \multicolumn{7}{|c|}{ Consideration of risk factors ${ }^{\mathrm{a}}$} \\
\hline Clinical & 65.0 & 50.0 & 75.0 & 50.0 & 4.93 & $0.02^{*}$ \\
\hline Historical & 22.0 & 20.0 & 12.0 & 17.5 & 2.25 & 0.13 \\
\hline Contextual & 8.5 & 13.5 & 11.0 & 12.0 & 1.79 & 0.18 \\
\hline Testing & 2.0 & 3.4 & 0.5 & 3.6 & 0.13 & 0.71 \\
\hline Demographic & 2.5 & 7.5 & 1.5 & 4.8 & 0.62 & 0.43 \\
\hline \multicolumn{7}{|c|}{ Perceived availability of factors ${ }^{b}$} \\
\hline Clinical & 8.2 & 1.5 & 8.6 & 1.6 & 1.50 & 0.22 \\
\hline Historical & 7.5 & 1.9 & 7.3 & 2.1 & 0.31 & 0.58 \\
\hline Contextual & 6.6 & 2.4 & 5.8 & 2.3 & 2.77 & 0.98 \\
\hline Testing & 5.7 & 3.0 & 5.7 & 3.1 & 0.22 & 0.93 \\
\hline
\end{tabular}

${ }^{a} N=1,080$ risk cues in total $(n=544$ cues for professionals and $n=536$ cues for paraprofessionals). Means and standard deviations represent the average percentage of risk cues listed by clinicians in each risk domain. For example, $65 \%$ of all risk cues listed by professional staff were in the clinical domain. ${ }^{\mathrm{h}} N=135(n=68$ professional staff and $n=67$ paraprofessional staff). Means and standard deviations represent average ratings of perceived availability by risk cue domain on a $0-10$ scale. For example, the average rating by professional staff for perceived availability of clinical factors was 8.2 out of a possible 10 . ${ }^{*} p<.05$.

\section{Clinical Decision-Making Task}

Hierarchical linear regression was used to analyze data on dangerousness judgments (see Table 2). The first model of the hierarchical regression involved controlling the variance in dangerousness judgments accounted for by treatment contexts and was statistically significant, indicating that contextual variables accounted for approximately $5 \%$ of the variance in dangerousness judgments. Afterward, the main effects of participant variables (gender, experience, training) on dangerousness judgments were entered into the next model of the hierarchical regression. On participants' judgments of dangerousness, there was a main effect for participants' gender. These main effects significantly contributed to the regression equation, and $R^{2}$ was significantly different from zero at the end of this second step but accounted for less than $1 \%$ of the variance in dangerousness judgments.

In the third model, the 12 cues derived from the PCL:SV were entered into the hierarchical regression equation. Analyses showed a statistically significant finding between judgments of dangerousness and adult antisocial behavior, lack of remorse, lack of em- pathy, poor behavioral controls, irresponsibility, grandiosity, impulsivity, and juvenile antisocial behaviors. It is important to note that clinical setting and participant variables were no longer significantly related to dangerousness judgments after psychopathy cues were entered into the regression model. This $R^{2}$ was significantly different from zero at the end of the third step and indicated that participants' ratings of psychopathy variables accounted for more than $60 \%$ of the variance in dangerousness judgments.

\section{Perceptions of Risk Factor Availability}

Regarding the survey on perceived availability of risk cues, descriptive analyses of composite scores of risk domains indicated that clinical information was perceived to be most readily available to staff, followed by contextual, historical, and testing data. Table 1 illustrates that this pattern did not differ between professionals and paraprofessionals and that this pattern mirrors findings above on the consideration of risk cues. Additional analyses showed that other clinician and setting characteristics did not change this overall pattern either. However, when ex- 
Table 2

Hierarchical Linear Regression Predicting Judgments of Dangerousness

\begin{tabular}{|c|c|c|c|c|c|c|}
\hline \multirow[b]{2}{*}{ Decision-making factors } & \multicolumn{2}{|c|}{ Model $1\left(R^{2}=.050\right)$} & \multicolumn{2}{|c|}{ Model $2\left(R^{2}=.057\right)$} & \multicolumn{2}{|c|}{ Model $3\left(R^{2}=.661\right)$} \\
\hline & $\beta$ & Sig & $\beta$ & Sig & $\beta$ & Sig \\
\hline \multicolumn{7}{|c|}{ Clinical setting or context } \\
\hline Forensic or civil context & -.157 & $.000^{* *}$ & -.174 & $.000 * *$ & .011 & .584 \\
\hline Admission-discharge condition & -172 & $.000^{* *}$ & -170 & $.000^{* *}$ & -.022 & .243 \\
\hline State hospital or crisis center & -.072 & $.002 * *$ & -.081 & $.000^{* *}$ & .004 & .846 \\
\hline \multicolumn{7}{|c|}{ Clinician variables } \\
\hline Clinician gender & & & .076 & $.014 *$ & .014 & .451 \\
\hline Clinician training & & & -.025 & .427 & .020 & .318 \\
\hline Clinician years of experience & & & -.027 & .396 & -.036 & .059 \\
\hline \multicolumn{7}{|c|}{ Psychopathy cues } \\
\hline Superficiality & & & & & -.021 & .332 \\
\hline Adult antisocial behavior & & & & & .104 & $.000^{* *}$ \\
\hline Deceitfulness & & & & & -.010 & .737 \\
\hline Lack of remorse & & & & & .293 & $.000 * *$ \\
\hline Lack of empathy & & & & & .076 & $.016^{*}$ \\
\hline Fails to take responsibility & & & & & .047 & .129 \\
\hline Impulsivity & & & & & .179 & $.000 * *$ \\
\hline Poor behavioral controls & & & & & .238 & $.000^{* *}$ \\
\hline Lacks realistic goals & & & & & .031 & .190 \\
\hline Irresponsible & & & & & .089 & $.002 * *$ \\
\hline Grandiosity & & & & & .061 & $.005^{* *}$ \\
\hline Juvenile antisocial acts & & & & & .097 & $.000^{* *}$ \\
\hline
\end{tabular}

Note. $\quad N=1,080$. DV $=$ Judgment of dangerousness $(1-8$ rating).

${ }^{*} p<.05 . \quad{ }^{* *} p<.01$.

amining specific cue domains, we found that there were some differences based on setting: Analyses of variance demonstrated that clinicians in the crisis setting, compared with state hospital settings, perceived that historical information was less available, $F(1$, $133)=4.699, p=.03$. With respect to specific risk factors, participants with more clinical experience also indicated that the PCL results were more likely to be available to them, $F(1,133)=4.028, p=.04$.

\section{Discussion}

Participants indicated considering clinical data most often when assessing violence risk, reporting that clinical data were also most readily available. Conversely, clinicians perceived formal testing information (e.g., PCL) to be least available and considered these data least often when they assessed patients' violence risk. Still, participants with greater clinical experience considered testing information more frequently and per- ceived PCL results to be more readily available. Further, although clinicians did not explicitly report using the PCL when evaluating violence risk, they did implicitly rely on psychopathy factors to arrive at judgments of dangerousness. Finally, the findings indicated that clinicians in crisis settings reported less availability of historical data typically needed to complete the PCL.

These results have several implications for improving violence risk assessment in clinical practice. First, the findings suggest that clinicians in public sector mental health settings may rely on readily available clinical information but at the same time discount less readily available historical and testing information, even though the latter variables have been shown to be most predictive of violence (Monahan \& Steadman, 1994). Researchers have studied how clinicians frame clinical tasks by examining typical errors and biases in decision making (Garb, 1998) and have identified a number of mental shortcuts (called "heuristics") used by 
human decision makers (Tversky \& Kahneman, 1981). Thus, clinicians in this sample may be using what is called the "availability heuristic" in which they make judgments based on what can be easily remembered, rather than on complete information. Indeed, many participants during data collection informally acknowledged forgetting key historical information from social work reports or psychological test results such as the PCL. McNiel (1998) has recommended that awareness of cognitive biases may improve clinicians' assessments of violence.

Empirical studies on improving decision making also suggest that important information should be made vivid and very easy to bring to mind-for example, with repetition and visual language (Garb, 1998). Applied to the current findings, this suggests that staff training or focus groups on risk assessment can be used to specifically address the need to incorporate historical and testing variables as well as clinical factors into decision making (especially for paraprofessionals). Efforts should be made to explore ways of summarizing critical risk information into a more readable format so that such information is more easily accessible to staff. For example, integration of historical and clinical risk factors could be considered more actively during regularly scheduled treatment reviews. Staff should review the patient's risk factors and risk levels in addition to reviewing the patient's treatment plan. If such a risk review were repeated at each treatment review, historical information relevant to risk assessment as well as PCL results would be more emphasized and better remembered. In this way, historical and testing data have a greater chance of being used to formulate patients' violence risk and of being integrated with relevant clinical data.

Another salient finding in this study regarded clinicians' consideration of psychopathy for assessing violence risk. The computerized decision-making task elucidates that the reason clinicians are not explicitly considering the PCL is not because they think psychopathy is irrelevant. Instead, the results indicate that clinical staff in public sector settings would be very amenable to using the PCL; the PCL would seem to have great intuitive appeal to clinicians. However, that more experienced staff perceived PCL results to be available reveals a need for more effort to target disseminating risk measure results (Borum, 1996; Douglas, Cox, \& Webster, 1999; Webster \& Cox, 1997). In particular, the results point out that educational training and/or procedural changes in public sector mental health settings will be most successful if they focus on improving violence risk communication (Heilbrun, O’Neill, Strohman, Bowman, \& Philipson, 2000; Heilbrun, Philipson, Berman, \& Warren, 1999). In other words, didactic training on the PCL or the risk assessment in general may be less effective than channeling efforts to make sure frontline staff members understand PCL results. Methods of conveying PCL results in a way that is user-friendly, clearly understood, consistently documented, and applicable to individual cases will likely help augment clinical consideration of psychopathy in this regard, especially so both mental health professionals and paraprofessionals can evaluate violence risk in a more scientifically validated way.

Finally, the findings imply that clinicians working in psychiatric emergency settings may have less historical information at their disposal compared with their counterparts in longer term inpatient settings (see Gardner et al., 1996a). This is consistent with other research showing that history of violence was documented in approximately a quarter of the charts at a crisis center (Elbogen, Mercado, Tomkins, \& Scalora, 2001). Malone, Szanto, Corbitt, and Mann (1995) also found that clinical reports in an acute psychiatric setting sometimes failed to document history of suicide attempts. Historical information, necessary to complete the PCL, may be difficult to obtain because of logistical constraints of the crisis center, because clients may be too psychotic to provide accurate information, or because clients refuse to sign releases of information when confronted with possible civil commitment. A number of actuarial screening tools have been developed (Gardner et al., 1996b; McNeil \& Binder, 1994). Most recently, results from the MacArthur Violence Risk Assessment Study have been used to construct the COVR (Classification of Violence Risk), a computerized actuarial risk assessment instrument for acute psychiatric settings that relies on readily available information (Monahan el al., 2005). Thus, the PCL may be less clinically feasible to use in such time-pressured settings compared with quicker risk assessment screens.

There are several limitations in this study that should be considered. This project was conducted in Lincoln, Nebraska; thus, future research will need to 
determine whether the results generalize to other jurisdictions. The question of generalizability is important because it could be pointed out that policies in some states or mental health center; mandate the use of actuarial measures (e.g., the forensic branch of the New York Office of Mental Health requires PCL administration). However, at the current time, this involves the minority of jurisdictions in the United States. Similarly, more work will be needed with comparable cohorts to assess whether clinical considerations of psychopathy and perceptions of risk factor availability are unique to the sample of clinicians who participated in this study.

Direct observation of the clinical process, and of scoring and reporting of the PCL itself, may have provided additional measurements of cue consideration and utilization (Mulvey \& Lidz, 1985, 1995). Also, there is a distinction between formal (request for dangerousness evaluations) and informal (risk decision making made by clinicians and paraprofessionals on a day-to-day basis) violence risk assessments; this study focuses on the latter. Finally, although it could be argued that the findings might be different if collected today, it should be noted that there was ample empirical evidence at the time of data collection to warrant clinical consideration of the PCL (e.g., a MEDLINE search indicated that there were over 200 publications using the PCL prior to data collection).

Mulvey and Lidz (1995) stated that mental health clinicians with varying types of training backgrounds assess varying types of violent behavior in varying circumstances. Consequently, efforts need to be made not only to increase accuracy of risk assessment, but also to understand how violence risk assessment occurs in actual practice. By describing how clinicians consider risk tools such as the PCL, we hope that this article will foster communication between researchers and practitioners and. ultimately, assist in transferring risk assessment technology to public sector mental health settings.

\section{References}

Barbaree, H. E., Seto, M. C., Langton, C. M., \& Peacock, E. J. (2001). Evaluating the predictive accuracy of six risk assessment instruments for adult sex offenders. Criminal Justice and Behavior, 28, 490-52 1.

Borum, R. (1996). Improving the clinical practice of violence risk assessment. American Psychologist, 51, 945956.
Bovasso, G. B., Alterman, A. I., Cacciola, J. S., \& Rutherford, M. J. (2002). The prediction of violent and nonviolent criminal behavior in a methadone maintenance population. Journal of Personality Disorders, 16, 360-373.

Bureau of Justice Statistics. (1999). Workplace violence 1993-1999. Retrieved May 8, 2004 from http://www.ojp. usdoj.gov/bjs/abstract/vw99.htm

Douglas, K. S., Cox, D. N., \& Webster, C. D. (1999). Violence risk assessment: Science and practice. Legal and Criminological Psychology, 4, 149-184.

Edens, J. F., Skeem, J. L., \& Cruise, K. R. (2001). Assessment of "juvenile psychopathy" and its association with violence: A critical review. Behavioral Sciences and the Law, 19, 53-80.

Elbogen, E. B., Mercado, C., Tomkins, A. J., \& Scalora, M. J. (2001). Clinical practice and violence risk assessment: Availability of MacArthur Risk Factors. In D. Farrington, C. R. Hollin, \& M. McMurran (Eds.), Sex and violence: The psychology of crimes and risk assessment (pp. 38-55). New York: Routledge.

Garb, H. N. (1998). Studying the clinician: Judgment research and psychological assessment. Washington, DC: American Psychological Association.

Gardner, W., Lidz, C. W., Mulvey, E. P., \& Shaw, E. C. (1996a). Clinical versus actuarial predictions of violence in patients with mental illnesses. Journal of Consulting and Clinical Psychology, 64, 602-609.

Gardner, W., Lidz, C. W., Mulvey, E. P., \& Shaw, E. C. (1996b). A comparison of actuarial methods for identifying repetitively-violent patients. Law and Human Behavior, 20, 35-48.

Gendreau, P., Goggin, C., \& Smith, P. (2002). Is the PCL$\mathrm{R}$ really the "unparalleled" measure of offender risk? A lesson in knowledge accumulation. Criminal Justice and Behavior, 29, 397-426.

Grann, M., Langstrom, N., Tengstrom, A,, \& Kullgren, G. (1999). Psychopathy (PCL-R) predicts violent recidivism among criminal offenders with personality disorders in Sweden. Law and Human Behavior, 23, 205-2 17.

Grann, M., \& Wedin, I. (2002). Risk factors for recidivism among spousal assault and spousal homicide offenders. Psychology, Crime \& Law, 8, 5-23.

Grisso, T., \& Tomkins, A. J. (1996). Communicating violence risk assessments. American Psychologist, 51, 928930.

Hare. R. D. (1991). The Hare Psychopathy Checklist-Revised. Toronto, Ontario, Canada: Multi-Health Systems.

Hare, R. D. (2003). The Hare Psychopathy Checklist-Revised (2nd ed.). Toronto, Ontario, Canada: Multi-Health Systems. 
Harris, G. T., Rice, M. E., \& Cornier, C. A. (2002). Prospective replication of the Violence Risk Appraisal Guide in predicting violent recidivism among forensic patients. Law and Human Behavior, 26, 377-394.

Hart, S. D., Hare, R. D., \& Forth, A. E. (1994). Psychopathy as a risk marker for violence: Development and validation of a screening version of the revised Psychopathy Checklist. In J. Monahan \& H. J. Steadman (Eds.). Violence and mental disorder: Developments in risk assessment (pp. 81-98). Chicago: University of Chicago Press.

Heilbrun, K. (1997). Prediction versus management models relevant to risk assessment: The importance of legal decision-making context. Law and Human Behavior, 21, 347-359.

Heilbrun, K., O’Neill, M. L., Strohman, L. K., Bowman, Q., \& Philipson, J. (2000). Expert approaches to communicating violence risk. Law and Human Behavior, 24, $137-$ 148.

Heilbrun, K., Philipson. J., Berman, L., \& Warren, L. (1999). Risk communication: Clinician's reported approaches and perceived values. Journal of American Academy of Psychiatry and Law, 27, 397-406.

Hox, J. J., \& Kreft, I. G. (1994). Multilevel analysis methods. Sociological Methods \& Research, 22, 283-299.

Keppel, G. (1991). Design and analysis: A researcher's handbook (3rd ed.). Englewood Cliffs, NJ: Prentice Hall.

Leger. D. W., \& Didrichsons, I. A. (1994). An assessment of data pooling and some alternatives. Animal Behaviour, 48, 823-832.

Looman, J., Abracen, J., \& Serin, R. (2005). Psychopathy, treatment change, and recidivism in high-risk, high-need sexual offenders. Journal of Interpersonal Violence, 20, $549-568$.

Louth, S. M., Hare, R. D., \& Linden, W. (1998). Psychopathy and alexithymia in female offenders. Canadian Journal of Behavioural Science, 30, 91-98.

Malone, K. M., Szanto, K., Corbitt, E. M., \& Mann, J. J. (1995). Clinical assessment versus research methods in the assessment of suicidal behavior. American Journal of Psychiatry, 152, 1601-1607.

McNiel, D. E. (1998). Empirically based clinical evaluation and management of the potentially violent patient. In P. M. Kleespies (Ed.), Emergencies in mental health practice: Evaluation and management (pp. 95-116). New York: Guilford Press.

McNiel, D. E., \& Binder, R. L. (1994). The relationship between acute psychiatric symptoms, diagnosis, and shortterm risk of violence. Hospital and Community Psychiatry, 45, 133-1 37.

Monahan, J., \& Steadman, H. (Eds.). (1994). Violence and mental disorder: Developments in risk assessment. Chi- cago: University of Chicago Press.

Monahan, J., Steadman, H. J., Robbins, P. C., Appelbaum, P., Banks, S., Grisso T., et al. (2005). An actuarial model of violence risk assessment for persons with mental disorders. Psychiatric Services, 56(7), 810-815.

Mulvey. E., \& Lidz, C. (1985). Back to basics: A critical analysis of dangerousness research in a new legal environment. Law and Human Behavior, 9, 209-218.

Mulvey, E., \& Lidz, C. (1995). Conditional prediction: A model for research on dangerousness to others in a new era. International Journal of Law and Psychiatry, 18, 129-143.

Quinsey, V. L., Harris, G. T., Rice, M. E., \& Cornier, C. A. (1998). Violent offenders: Appraising and managing risk. Washington, DC: American Psychological Association.

Salekin, R. T., Rogers, R., \& Sewell, K. W. (1996). A review and meta-analysis of the Psychopathy Checklist and Psychopathy Checklist-Revised: Predictive validity of dangerousness. Clinical Psychology: Science and Practice, 3, 203-215.

Skeem, J. L., Edens, J. F., \& Camp, J. (2004). Are there ethnic differences in levels of psychopathy? A meta-analysis. Law and Human Behavior, 28, 505-527.

Skeem, J. L., \& Mulvey, E. P. (2001). Psychopathy and community violence among civil psychiatric patients: Results from the MacArthur Violence Risk Assessment Study. Journal of Consulting and Clinical Psychology, 69, 358-374.

Steadman, H., Monahan, J., Appelbaum, P., Grisso, T.. Mulvey, E., Roth, L., et al. (1994). Designing a new generation of risk assessment research. In J. Monahan \& $\mathrm{H}$. Steadman (Eds.), Violence and mental disorder: Developments in risk assessment (pp. 297-318). Chicago: University of Chicago Press.

Tversky, A,, \& Kahneman, D. (1981, January 30). The framing of decisions and the psychology of choice. Science, 211, 453-458.

Webster, C. D., \& Cox, D. (1997). Integration of nomothetic and ideographic positions in risk assessment: Implications for practice and the education of psychologists and other mental health professionals. American Psychologist, 52, 1245-1247.

Webster, C. D., Douglas, K. S., Eaves, D., \& Hart, S. D. (1997). The HCR-20 scheme: The assessment of dangerousness and risk (Version 2). Burnaby, British Columbia, Canada: Simon Fraser University and Forensic Psychiatric Services Commission of British Columbia.

Received December 29, 2004 Revision received July 19, 2005 Accepted July 27, 2005 